\title{
Preparação e Caracterização de Nanofibras de Nanocompósitos de Poliamida 6,6 e Argila Montmorilonita
}

\author{
Camila R. dos Santos, Rosario E. S. Bretas \\ Departamento de Engenharia de Materiais, UFSCar \\ Márcia C. Branciforti \\ Departamento de Engenharia de Materiais, UFSCar \\ Departamento de Engenharia de Materiais, Aeronáutica e Automobilística, EESC-USP \\ Thomas Canova \\ Rhodia Poliamida e Especialidades
}

\begin{abstract}
Resumo: A busca por fibras poliméricas com diâmetros na ordem de nanômetros tem sido alvo dos pesquisadores e das indústrias, sendo que essas fibras possuem diversas aplicações. Estas fibras podem ser produzidas pelo processo de eletrofiação a partir da solução polimérica. Neste trabalho, fibras de nanocompósitos de poliamida 6,6 e argila montmorilonita foram obtidas via mistura no estado fundido, seguida da eletrofiação da solução dessa mistura. Nanocompósitos com três diferentes concentrações de argila, 2, 3 e 4\% em peso, foram obtidos via mistura no estado fundido, e soluções desses nanocompósitos em ácido fórmico foram preparadas em diferentes concentrações. A influência da adição de argila, da concentração da solução de nanocompósitos, da variação do campo elétrico aplicado sobre as propriedades das misturas, das soluções e finalmente sobre o diâmetro médio das fibras obtidas foi estudada. Medidas de difração de raios-X a altos ângulos (DRX) e de microscopia eletrônica de transmissão (MET) comprovaram que o processo de eletrofiação foi eficiente na manutenção da esfoliação da argila das fibras obtidas. Resultados de microscopia eletrônica de varredura (MEV) e de calorimetria de varredura diferencial (DSC) permitiram concluir que as fibras obtidas possuem diâmetros médios na ordem de nanômetros, são cilíndricas, não porosas, possuem baixo grau de cristalinidade e apresentam solvente residual. A adição de argila aumentou ligeiramente a viscosidade da solução e consequentemente um pequeno aumento do diâmetro médio das nanofibras foi observado. Por outro lado, um aumento do diâmetro médio das nanofibras com o aumento da concentração polimérica foi observado. Em relação ao campo elétrico aplicado notou-se uma tendência na diminuição do diâmetro médio das fibras à medida que este parâmetro diminui.
\end{abstract}

Palavras-chave: Poliamida 6,6, PA6,6, Eletrofiação, Nanofibras, Nanocompósitos, Argila.

\section{Preparation and Characterization of Nanofibers of Polyamide 66 and Montmorillonite Clay Nanocomposites}

Abstract: The search for polymeric fibers with diameters in the scale of nanometers has been the great objective of researchers and industry, since these fibers have many applications. They can be produced by an electrospinning process from a polymeric solution. In this work, nanocomposites' fibers of polyamide 66 and montmorillonite clay were obtained by melt mixing, following by electrospinning of the solution. Nanocomposites with three different clay concentrations, 2, 3 and $4 \mathrm{wt} . \%$, were obtained by melt mixing, and solutions of these nanocomposites in formic acid were prepared at different concentrations. The influence of the clay addition, nanocomposites' solution concentration, variation of the applied electric field on the mixture and solutions properties and on the average diameter of the nanofibers was studied. Wide-angle X-ray (WAXD) and transmission electron microscopy (TEM) measurements showed that the process of electrospinning was efficient in the maintenance of the clay exfoliation in the fibers. Results of scanning electron microscopy (SEM) and differential scanning calorimetry (DSC) showed that the fibers had average diameters of the order of nanometers, were cylindrical and not porous, having low degree of crystallinity and residual solvent. The addition of clay increased slightly the viscosity of the polymeric solution, which increased the nanofibers average diameter. It was also observed that the increase in the fiber diameters was proportional to the increase of the polymer concentration in the solution. Regarding the applied electric field, it was observed a tendency to reduction in the average diameter of the fibers with the reduction of this parameter.

Keywords: Polyamide 66, PA66, Electrospinning, Nanofibers, Nanocomposites, Clay.

\section{Introdução}

A produção de nanocompósitos poliméricos com argilas ou silicatos lamelares (em camadas) pode ser feita por meio de intercalação do polímero em solução (camadas de argila são previamente inchadas no solvente, misturando-se então o polímero, sendo o solvente posteriormente evaporado), polimerização in situ do monômero (polimerização ocorre entre as camadas do silicato) e a intercalação do polímero fundido. Esta última é a alternativa tecnológica mais viável uma vez que não é requerido o uso de solventes e os equipamentos utilizados (extrusoras, etc) são aqueles que já se encontram disponíveis em linhas de produção industrial ${ }^{[1]}$. Entretanto a melhora significativa nas diversas propriedades somente é alcançada quando se atinge um determinado nível de intercalação do polímero, no qual as lamelas ou camadas da argila estão completamente esfoliadas; para tanto é necessário escolher campos de fluxo nos quais a tensão ou a deformação aplicada auxiliem na delaminação da $\operatorname{argila}^{[2-4]}$. De uma maneira geral, a preparação de nanocompósitos via mistura no estado fundido é influenciada não somente pelas condições de processamento do polímero, mas também pelas interações físicoquímicas entre a matriz polimérica e a superfície das argilas.

Nanocompósitos de polímero com argilosilicatos podem ser utilizados em uma ampla faixa de novas aplicações, e em

Autor para correspondência: Rosario E. S. Bretas, Departamento de Engenharia de Materiais, Universidade Federal de São Carlos - UFSCar, Rod. Washington Luis, Km 235, CP 676, CEP 13565-905, São Carlos, SP, Brasil, e-mail: bretas@ufscar.br 
uma escala competitiva com outros materiais convencionais. A nanoargila montmorilonita vem sendo fonte de constantes estudos de intercalação química e esfoliação, pois possui origem natural e vantagens como boas capacidade de delaminação, alta resistência a solventes, estabilidade térmica para suportar os processos de transformação e elevada razão de aspecto $^{[1,5-12]}$. Nanofibras de nanocompósitos obtidas pelo processo de eletrofiação e com propriedades especiais têm sido amplamente apresentadas na literatura recente ${ }^{[13-19]}$.

As fibras produzidas pelo processo de eletrofiação diferem das produzidas pelos processos convencionais em dois principais fatores: as fibras eletrofiadas possuem dimensões bem menores da ordem de nanômetros e são interligadas. Devido a estes fatores, são conhecidas como mantas não tecidas ou membranas. A elevada área superficial e a elevada razão de aspecto desses materiais favorecem suas variadas aplicações, dentre elas: roupas protetoras, filtração, cobertura de feridas, membranas, vasos sangüíneos artificiais, entre outras. Nosso grupo de pesquisa deu iniciou a suas atividades no campo de eletrofiação em 2003 com o projeto da Dra. L. Guerrini ${ }^{[18,20]}$. Em 2007 foram depositadas duas patentes em parceria com a empresa Rhodia ${ }^{\circledR}$ Poliamida e Especialidades ${ }^{[13,21]}$. Este mesmo grupo tem processado nanofibras de vários outros sistemas poliméricos como os biopolímeros poli(álcool vinílico) $)^{[22,23]}$, poli(ácido lático $)^{[24,25]}$, poli( $(\varepsilon$-caprolactona) $(\mathrm{PCL})^{[26]}$, poli(hidroxibutirato $)^{[27]}$ poli(butileno adipato-co-tereftalato) $(\mathrm{PBAT})^{[28]}$, e nanocompósitos de poliamida 6/montmorilonita ${ }^{[14]}$, $\mathrm{PCL} /$ montmorilonita ${ }^{[29]}$ e de PBAT/montmorilonita ${ }^{[28]}$.

Resultados publicados ${ }^{[18,20,21]}$ mostram que poliamida 6,6 de diferentes massas molares podem ser eletrofiadas utilizando-se ácido fórmico como solvente. Foi observado que quanto menor a massa molar da poliamida 6,6, menor é o diâmetro médio das nanofibras obtidas, entretanto, um valor crítico de massa molar ponderal e numérica média é necessário para se ter a eletrofiação. Foram obtidas fibras com diâmetro médio entre 60 e $200 \mathrm{~nm}$. Também foi observado que o diâmetro médio das nanofibras diminui com a diminuição da concentração da solução polimérica, com o aumento na tensão aplicada e quanto maior a quantidade de grupos terminais carboxílicos. A presença de um $1 \%$ em peso de sal iônico, $\mathrm{NaCl}$, duplica a condutividade elétrica da solução e aumenta o diâmetro médio das nanofibras. As nanofibras obtidas apresentam baixa cristalinidade quando comparadas com as fibras têxteis e são observadas mudanças na estrutura cristalina de $\alpha$ para $\gamma$, como ocorre no processo de fiação convencional, devido às altas tensões sob elongação durante o processo de eletrofiação.

Entretanto, há poucos estudos sobre a eletrofiação de nanocompósitos de poliamida 6,6 com argila. Ristolainem e colaboradores $^{[30]}$ avaliaram duas formas diferentes de adição de argila montmorilonita (Cloisite ${ }^{\circledR}$ 15B) na eletrofiação de soluções de poliamida 6,6 em ácido fórmico e álcool polivinílico em água. A primeira consistiu em dispersar a argila durante a preparação das soluções e a segunda, em adicionar a argila durante a síntese dos polímeros. Os resultados demonstraram que se obtinha um menor tamanho de partícula de argila quando a mesma era adicionada durante a polimerização. Os defeitos tipo gota das nanofibras foram evidentes somente nas mantas de poliamida 6,6 com argila. Estas mantas apresentaram menores ângulos de contato e menor absorção da água.

O objetivo deste trabalho foi estudar a obtenção de nanofibras de nanocompósitos de poliamida 6,6 e argila montmorilonita Cloisite ${ }^{\circledR}$ $30 \mathrm{~B}$ via eletrofiação. Para tanto, duas diferentes vias de obtenção dos nanocompósitos, parâmetros do processo e concentrações das soluções foram variados. As misturas, as soluções e as mantas obtidas foram caracterizadas através de ensaios de difração de
raios-X (DRX), reologia, condutividade elétrica, tensão superficial, calorimetria de varredura diferencial (DSC), microscopia eletrônica de varredura (MEV) e microscopia eletrônica de transmissão (TEM).

\section{Experimental}

\section{Materiais}

Os materiais utilizados foram: poliamida 6,6 (PA6,6) (póscondensada 24 horas a $150{ }^{\circ} \mathrm{C}$ ) com densidade de $1,14 \mathrm{~g} . \mathrm{cm}^{-3}$, $\mathrm{M}_{\mathrm{w}}=33.500 \mathrm{~g} \cdot \mathrm{mol}^{-1}, \mathrm{~T}_{\mathrm{g}} \mathrm{de} 45-65^{\circ} \mathrm{C}, \mathrm{T}_{\mathrm{f}}$ de $263^{\circ} \mathrm{C}$, grupos terminais carboxílicos de $9,78 \times 10^{-5} \mathrm{~mol} . \mathrm{g}^{-1}$ e os grupos terminais amínicos de $3,46 \times 10^{-5}$ mol. $\mathrm{g}^{-1}$, cedida pela Rhodia ${ }^{\circledR}$ Poliamida e Especialidades (Santo André) $)^{[18,31,32]}$, e argila Cloisite ${ }^{\circledR} 30 \mathrm{~B}$, da Southern Clay Products Inc. (USA). Essa argila é uma montmorilonita natural modificada organicamente com sal de amônio quaternário ${ }^{[33]}$. O solvente utilizado foi o ácido fórmico com grau de pureza de $85 \%$ da marca Synth. Esse ácido possui densidade relativa $(\rho)$ de 1,22, viscosidade de $1,70 \mathrm{Cp}, \mathrm{T}_{\mathrm{eb}}$ de $101^{\circ} \mathrm{C}, \mathrm{T}_{\mathrm{f}}$ de $8,6^{\circ} \mathrm{C}$, pressão de vapor $\left(\mathrm{P}_{\mathrm{v}}\right)$ de $40 \mathrm{mmHg}$ a $24{ }^{\circ} \mathrm{C}$, sendo um bom solvente para poliamida, apresentando toxidade moderada e baixo custo ${ }^{[34]}$.

\section{Preparação dos nanocompósitos}

Os nanocompósitos de PA 6,6 foram preparados por duas vias: mistura no estado fundido e mistura em solução, com o objetivo de obter e comparar a esfoliação e/ou intercalação da nanoargila na matriz polimérica da manta eletrofiada.

\section{Via mistura no estado fundido}

Inicialmente a PA 6,6, e a argila foram secas em estufa á vácuo a $80{ }^{\circ} \mathrm{C}$ por 14 horas para remoção da umidade. A mistura no estado fundido foi realizada no reômetro de torque Haake, modelo Rheomics 610, com um par de rotores contra-rotacionais e semi-interpenetrantes. As condições de processamento utilizadas foram: temperatura de processamento: $285{ }^{\circ} \mathrm{C}$; rotação: $60 \mathrm{rpm}$; e tempo que o material permaneceu dentro da câmera: 5 minutos. Foram preparados nanocompósitos com concentrações de 2, 3 e $4 \%$ em peso de argila. Neste trabalho esses nanocompósitos serão denominados por N2, N3 e N4, respectivamente. As soluções desses nanocompósitos em ácido fórmico foram preparadas em recipientes fechados, em uma capela, sob agitação mecânica e em banho-maria a $40{ }^{\circ} \mathrm{C}$ por 2 horas. As concentrações finais dessas soluções estão descritas na Tabela 1 .

Tabela 1. Propriedades das soluções preparadas a partir dos nanocompósitos obtidos via mistura no estado fundido. Concentração de argila $\left(\mathrm{C}_{\text {argila }}\right)$, concentração de polímero $\left(\mathrm{C}_{\text {polímero }}\right)$, condutividade elétrica $(K)$, tensão superficial $(\tau)$ e viscosidade zero $\left(\eta_{0}\right)$.

\begin{tabular}{lccccc}
\hline Amostra & $\begin{array}{c}\mathbf{C}_{\text {argila }} \\
\left(\boldsymbol{\%} \mathbf{m . V}^{-1}\right)\end{array}$ & $\begin{array}{c}\mathbf{C}_{\text {polimero }} \\
\left(\boldsymbol{\%} \mathbf{m . V}^{-1}\right)\end{array}$ & $\begin{array}{c}K \\
\left(\mathbf{m S . c m}^{-1}\right)\end{array}$ & $\left.\begin{array}{c}\tau \\
(\mathbf{m N . m}\end{array} \mathbf{m}^{-1}\right)$ & $\begin{array}{c}\eta_{\mathbf{o}} \\
(\mathbf{P a . s})\end{array}$ \\
\hline N2-20 & 2 & 20,0 & 3,8 & $40,3 \pm 0,6$ & 0,17 \\
N2-22,5 & 2 & 22,5 & 3,4 & $40,6 \pm 0,6$ & 0,29 \\
N2-25 & 2 & 25,0 & 3,3 & $39,0 \pm 0,6$ & 0,50 \\
N3-20 & 3 & 20,0 & 3,3 & $38,3 \pm 0,6$ & 0,25 \\
N3-22,5 & 3 & 22,5 & 3,2 & $41,3 \pm 0,6$ & 0,41 \\
N3-25 & 3 & 25,0 & 2,9 & $43,6 \pm 0,6$ & 0,65 \\
N4-20 & 4 & 20,0 & 3,0 & $45,0 \pm 0,6$ & 0,30 \\
N4-22,5 & 4 & 22,5 & 3,0 & $44,0 \pm 0,6$ & 0,54 \\
N4-25 & 4 & 25,0 & 3,0 & $44,6 \pm 0,6$ & 0,83 \\
\hline
\end{tabular}




\section{Via mistura em solução}

Inicialmente, soluções de PA 6,6/ácido fórmico (S1) foram preparadas em recipientes fechados, em uma capela, com agitação mecânica por 2 horas e em banho-maria a $40^{\circ} \mathrm{C}$. Paralelamente, as suspensões de Cloisite ${ }^{\circledR}$ 30B/ácido fórmico (S2) foram preparadas também em recipientes fechados, sob exaustão, em banho-maria e expostas ao ultra-som à temperatura ambiente. Posteriormente, essas duas soluções foram misturadas e expostas ao ultra-som por diferentes tempos e à temperatura ambiente. A Tabela 2 apresenta as concentrações finais dessas soluções, as condições de preparação e a nomenclatura das mesmas.

\section{Eletrofiação das soluções}

Para a eletrofiação das soluções poliméricas foi utilizado o equipamento descrito em detalhes na literatura ${ }^{[20,22,24]}$. Usou-se uma seringa de vidro de $20 \mathrm{~mL}$ com uma agulha do tipo Hamilton com diâmetro de 1,20 mm e comprimento de $30 \mathrm{~mm}$. A eletrofiação foi realizada em ambiente com temperatura $\left(25^{\circ} \mathrm{C}\right)$ e umidade $(60 \%)$ controladas, variando-se o campo elétrico aplicado de $5,0 \mathrm{kV} . \mathrm{cm}^{-1}$ e $2,5 \mathrm{kV} \cdot \mathrm{cm}^{-1}$. Todas as soluções foram eletrofiadas nas mesmas condições, independentemente do modo de obtenção, via mistura no estado fundido ou via mistura em solução. As mantas eletrofiadas, com dimensões aproximadas de $180 \mathrm{~cm}$ (largura) $\times 250 \mathrm{~cm}$ (comprimento) $\times 0,05 \mathrm{~cm}$ (espessura) foram coletadas sobre folha de papel alumínio. A Tabela 3 apresenta as 18 condições de eletrofiação resultantes e a nomenclatura utilizada para as mantas obtidas.

\section{Caracterização dos nanocompósitos}

Medidas de DRX dos nanocompósitos obtidos via mistura no estado fundido e das mantas eletrofiadas foram realizadas em um difratômetro da marca Siemens, modelo D5000, utilizando radiação de $\mathrm{Cu}_{{ }_{\mathrm{K}}} \alpha(\lambda=1,5458 \AA$ A ) filtrada por ferro, operando a $50 \mathrm{kV}$ e $30 \mathrm{~mA}$, e na faixa de varredura de $2 \theta$ entre 0,6 e $10^{\circ}$.

A viscosidade a baixas taxas de cisalhamento dos nanocompósitos foi medida em um reômetro ARES de deformação controlada da Rheometrics Scientific, utilizando-se geometria de placas paralelas com diâmetro de $25 \mathrm{~mm}$ e distância entre as placas de $1 \mathrm{~mm}$. A viscosidade foi medida em função da taxa de cisalhamento $(\gamma)$ na faixa de 0,01 até $100 / \mathrm{s}$ e na temperatura de $280{ }^{\circ} \mathrm{C}$ (temperatura de processamento no Haake). As viscosidades das soluções também foram medidas a baixas $\gamma$, porém, utilizando geometria tipo Couette (cilindros concêntricos de 25 e $27 \mathrm{~mm}$ ).

A condutividade elétrica $(K)$ das soluções foi determinada utilizando-se um condutivímetro, marca Micronal, modelo B330 equipado com eletrodo de platina. Medidas da tensão superficial $(\tau)$ das soluções foram realizadas em um tensiômetro de marca Krüss, modelo K6, com anel de platina e através do método de du Nöy ${ }^{[35]}$.

A morfologia das mantas eletrofiadas foi caracterizada por MEV, utilizando-se o equipamento da Philips modelo FEG-XL30,

Tabela 2. Soluções preparadas via mistura em solução.

\begin{tabular}{lccc}
\hline Amostra & $\begin{array}{c}\text { Concentração } \\
\text { da solução S1 } \\
\left(\% \mathbf{m}^{-1}\right)\end{array}$ & $\begin{array}{c}\text { Concentração da } \\
\text { solução S2 }\left(\% \mathbf{m} . \mathbf{V}^{-1}\right) ; \\
(\text { tempo, em horas, } \\
\text { exposição ao ultra-som) })\end{array}$ & $\begin{array}{c}\text { Tempo de } \\
\text { exposição ao } \\
\text { ultra-som } \\
\text { S1 + S2 (horas) }\end{array}$ \\
\hline U-2 & 20,0 & 2,$0 ;(2)$ & 1 \\
U-2,5 & 20,0 & 2,$5 ;(2)$ & 2 \\
U-3 & 20,0 & 3,$0 ;(2)$ & 3 \\
U-3,5 & 20,0 & 3,$5 ;(3)$ & 3 \\
U-4 & 20,0 & 4,$0 ;(4)$ & 3 \\
\hline
\end{tabular}

operando entre $10-20 \mathrm{kV}$, sendo as amostras recobertas com uma fina camada de ouro, e por MET utilizando um microscópio da marca Philips, modelo CM120, operando a 120 kV. Os diâmetros das nanofibras obtidas foram quantificados a partir das micrografias usando o programa Image ProPlus ${ }^{\circledR}$ 4.5. Em cada micrografia foi medido o diâmetro de 150 fibras.

Medidas de DSC foram realizadas em um calorímetro de fluxo de calor da marca TA Instruments, modelo Q100. Utilizou-se massa aproximada de $6 \mathrm{mg}$ de amostra, realizando medidas na faixa de 30 a $300{ }^{\circ} \mathrm{C}$ com taxa de $10{ }^{\circ} \mathrm{C} / \mathrm{min}$. O grau de cristalinidade $(\% \mathrm{C})$ das amostras foi calculado através da Equação 1:

$$
\% C=\frac{\Delta \mathrm{H}_{m}}{\Delta \mathrm{H}_{0}} \times 100
$$

onde: $\Delta \mathrm{H}_{m}$ é a entalpia de fusão da amostra e $\Delta \mathrm{H}_{0}$ é a entalpia de fusão da poliamida $6,6100 \%$ cristalino, 206,0 J.g ${ }^{-1[32]}$. A porcentagem de solvente residual $\left(\mathrm{X}_{\mathrm{r} . \mathrm{s}}\right)$ nas mantas foi calculada através da Equação 2:

$$
\mathrm{X}_{\mathrm{r} . \mathrm{s}}=\frac{\mathrm{m}}{\mathrm{m}_{\mathrm{T}}} \times 100
$$

onde: $\mathrm{m}_{\mathrm{T}}$ é a massa total da amostra e $\mathrm{m}$ é a massa vaporizada de ácido fórmico calculada pela entalpia de vaporização $\left(\Delta \mathrm{H}_{\mathrm{v}}\right)$ por: $\Delta \mathrm{H}_{\mathrm{v}}=\mathrm{m}(\mathrm{c} \Delta \mathrm{T}+\mathrm{L})$ onde $\Delta \mathrm{T}=$ (temperatura final de vaporização - temperatura inicial de vaporização), c é o calor específico do ácido fórmico no estado líquido, $2169 \mathrm{~J}_{\mathrm{Jg}} \mathrm{kg}^{-1} \mathrm{e} \mathrm{L}$ é o calor latente de vaporização do ácido fórmico, 41,4 × 106 J.kg-1[32].

\section{Resultados e Discussão}

\section{Caracterização dos nanocompósitos obtidos via mistura no estado fundido}

Os difratogramas de DRX da argila e dos nanocompósitos $\mathrm{N} 2, \mathrm{~N} 3$ e N4 obtidos por mistura do fundido estão apresentado na

Tabela 3. Condições de eletrofiação das soluções de PA 6,6/ácido fórmico/

\begin{tabular}{|c|c|c|c|c|c|}
\hline & Amostra & $\begin{array}{c}\text { Concentração } \\
\text { de argila } \\
(\% \mathrm{~m})\end{array}$ & $\begin{array}{c}\text { Concentração } \\
\text { da solução } \\
\text { polimérica } \\
\left(\% \mathrm{~m} . \mathrm{V}^{-1}\right)\end{array}$ & $\begin{array}{c}\text { Campo } \\
\text { elétrico } \\
\text { aplicado } \\
\left(\mathbf{k V} \cdot \mathrm{cm}^{-1}\right)\end{array}$ & $\begin{array}{c}\text { Diâmetro } \\
\text { médio das } \\
\text { nanofibras } \\
(\mathrm{nm})\end{array}$ \\
\hline \multirow{18}{*}{ 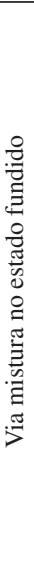 } & N2F20A & 2,0 & 20,0 & 5,0 & $83 \pm 27$ \\
\hline & $\mathrm{N} 2 \mathrm{~F} 20 \mathrm{~B}$ & 2,0 & 20,0 & 2,5 & $83 \pm 22$ \\
\hline & $\mathrm{N} 2 \mathrm{~F} 22 \mathrm{~A}$ & 2,0 & 22,5 & 5,0 & $134 \pm 22$ \\
\hline & N2F22B & 2,0 & 22,5 & 2,5 & $119 \pm 26$ \\
\hline & $\mathrm{N} 2 \mathrm{~F} 25 \mathrm{~A}$ & 2,0 & 25,0 & 5,0 & $144 \pm 32$ \\
\hline & $\mathrm{N} 2 \mathrm{~F} 25 \mathrm{~B}$ & 2,0 & 25,0 & 2,5 & $139 \pm 22$ \\
\hline & N3F20A & 3,0 & 20,0 & 5,0 & $73 \pm 22$ \\
\hline & N3F20B & 3,0 & 20,0 & 2,5 & $64 \pm 12$ \\
\hline & N3F22A & 3,0 & 22,5 & 5,0 & $122 \pm 34$ \\
\hline & N3F22B & 3,0 & 22,5 & 2,5 & $138 \pm 36$ \\
\hline & N3F25A & 3,0 & 25,0 & 5,0 & $85 \pm 34$ \\
\hline & N3F25B & 3,0 & 25,0 & 2,5 & $90 \pm 30$ \\
\hline & N4F20A & 4,0 & 20,0 & 5,0 & $70 \pm 21$ \\
\hline & N4F20B & 4,0 & 20,0 & 2,5 & $71 \pm 22$ \\
\hline & N4F22A & 4,0 & 22,5 & 5,0 & $85 \pm 30$ \\
\hline & N4F22B & 4,0 & 22,5 & 2,5 & $97 \pm 24$ \\
\hline & N4F25A & 4,0 & 25,0 & 5,0 & $146 \pm 27$ \\
\hline & $\mathrm{N} 4 \mathrm{~F} 25 \mathrm{~B}$ & 4,0 & 25,0 & 2,5 & $81 \pm 26$ \\
\hline శ్ & U2FA & 2,0 & 20,0 & 5,0 & - \\
\hline כ) & $\mathrm{U} 2,5 \mathrm{FA}$ & 2,5 & 20,0 & 5,0 & - \\
\hline ฮี & U3FB & 3,0 & 20,0 & 2,5 & - \\
\hline 苞 & $\mathrm{U} 3,5 \mathrm{FA}$ & 3,5 & 20,0 & 5,0 & - \\
\hline$\stackrel{\pi}{7}$ & U4FB & 4,0 & 20,0 & 2,5 & - \\
\hline
\end{tabular}
Cloisite ${ }^{\circledR}$ 30B. 
Figura 1. O difratograma da argila apresenta um pico em $2 \theta=4,8^{\circ}$ referente ao plano (001) o qual corresponde ao espaçamento basal de $1,8 \mathrm{~nm}$. Os difratogramas dos nanocompósitos não apresentam pico de difração, indicando a formação de estruturas esfoliadas nos três nanocompósitos.

Os resultados das medidas de viscosidade em função da taxa de cisalhamento da PA 6,6 processada e dos nanocompósitos $\mathrm{N} 2$, N3 e N4 obtidos por mistura no estado fundido, ou seja, todos processados no Haake, podem ser visualizadas na Figura 2. Observa-se que todos os materiais, inclusive a PA 6,6 processada, apresentaram mesmo comportamento, podendo-se observar dois platôs Newtonianos: o primeiro até aproximadamente $1 \mathrm{~s}^{-1}$ e o segundo até aproximadamente $10^{1} \mathrm{~s}^{-1}$. Já acima desta taxa o material comportou-se como um fluído pseudoplástico, ou seja, a viscosidade diminuiu com o aumento da taxa de cisalhamento. A presença dos dois platôs pode ser atribuída à hidrólise da PA66 ${ }^{[37]}$; sabe-se que quando a secagem das poliamidas é incompleta e estas possuem um alto conteúdo de água, as reações de policondensação são deslocadas para a esquerda, ocasionando hidrólise e diminuição do peso molecular das mesmas. No caso de nanocompósitos é recomendado, inclusive, que os tempos de secagem sejam maiores do que os da poliamida pura.

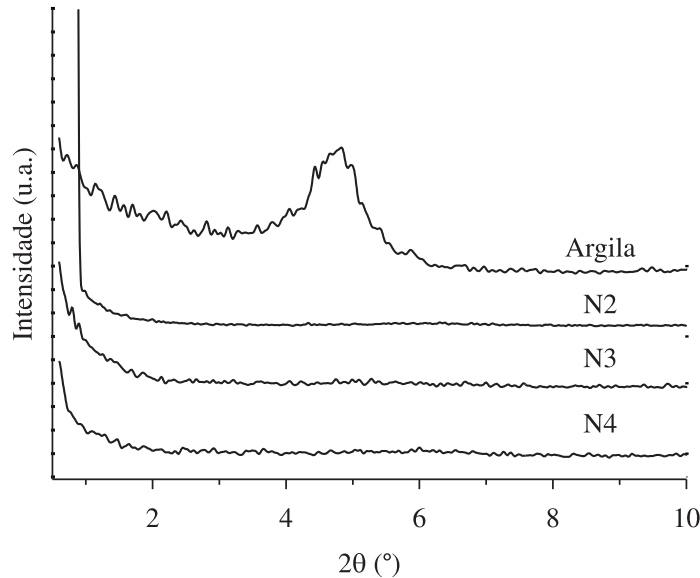

Figura 1. Difratogramas de DRX da argila Cloisite ${ }^{\circledR} 30 \mathrm{~B}$ e dos nanocompósitos de PA 6,6 com argila N2, N3 e N4.

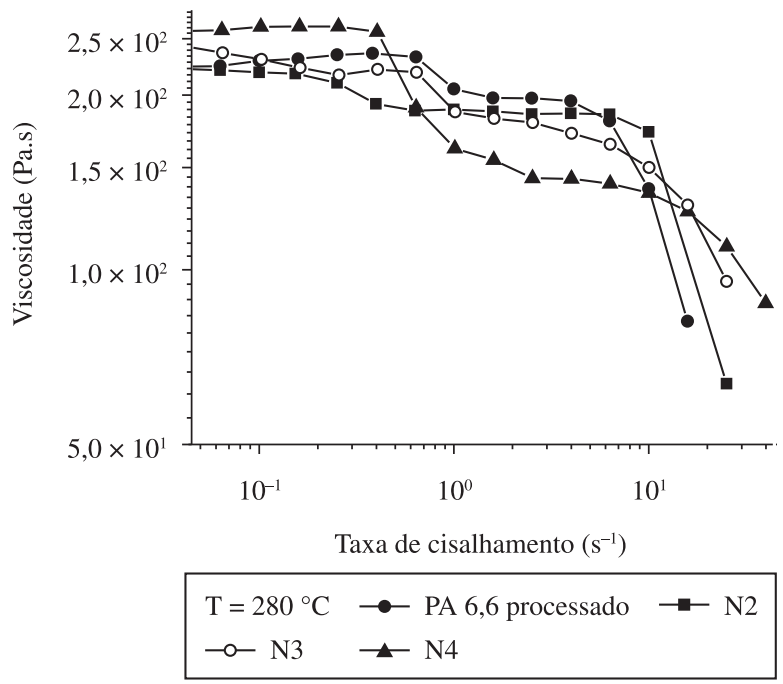

Figura 2. Curvas de viscosidade em função da taxa de cisalhamento da PA 6,6 processada e dos nanocompósitos N2, N3 e N4 obtidos via mistura no estado fundido.
Os nanocompósitos N2 e N3 apresentam comportamento similar ao da PA 6,6 processada. Porém o nanocompósito N4 teve maior decréscimo da viscosidade que a PA 6,6 processada acima de $10^{\circ}$ /s, isto é, a hidrólise neste material foi maior devido a que tinha maior quantidade de nanoargila (que absorve água).

\section{Caracterização das soluções poliméricas}

A condutividade elétrica das 9 soluções em ácido fórmico dos nanocompósitos obtidos via mistura no estado fundido está também apresentada na Tabela 1. Analisando os resultados é possível observar que à medida que se aumenta a concentração da solução diminui a condutividade. Resultados semelhantes também foram observados por $\mathrm{Li}$ e colaboradores ${ }^{[16]}$, que encontraram valores de condutividade de 4,6 e 4,3 mS.cm ${ }^{-1}$ e Suphapol e colaboradores ${ }^{[37]}$ com valores de 4,2 mS.cm ${ }^{-1}$, ambos trabalhando com poliamida 6 e ácido fórmico. Uma diminuição na condutividade também é observada quando se aumenta a quantidade de argila na solução. Porém, para soluções com $4 \%$ em peso de argila, percebe-se uma tendência de estabilização da condutividade. Guerrini e colaboradores $^{[18,20]}$ encontraram para a PA 6,6 em ácido fórmico valores entre 4,5 e $4,9 \mathrm{mS} . \mathrm{cm}^{-1}$. Portanto, pode-se concluir que a adição de argila diminuiu a condutividade elétrica da solução. Assim, os campos elétricos necessários para a eletrofiação dos nanocompósitos deverão ser maiores que os utilizados para a PA 6,6 pura.

Resultados de tensão superficial das soluções dos nanocompósitos obtidos via mistura no estado fundido também foram apresentados na Tabela 1. Esses resultados evidenciam que no geral, a adição de argila influência na tensão superficial da solução, de modo a aumentar esse parâmetro, ou seja, o acréscimo da fração volumétrica da carga proporciona maior resistência ao sistema. Apenas a solução N3-20 fugiu a essa tendência. Em relação à concentração da solução, pode-se afirmar que não existe uma relação direta entre a tensão superficial e concentração da solução. Cabe ressaltar que, sendo a solução um sistema trifásico, não se conhecem as forças que estão agindo na resistência à tensão, podendo ser ela proveniente do solvente, do polímero, da argila ou por fim de uma combinação entre eles. Outros autores ${ }^{[14,16,18,20]}$ admitem não terem observado uma dependência entre a concentração da solução e a tensão superficial de soluções semelhantes à deste estudo.

Para avaliar a influência da concentração polimérica das soluções e da concentração de argila dos nanocompósitos no diâmetro final das nanofibras obtidas, foram realizadas medidas de viscosidade em regime permanente de cisalhamento das soluções. As Figuras 3,4 apresentam os resultados das soluções de PA 6,6 (grãos e processada no Haake), e dos nanocompósitos N2, N3 e N4 nas diferentes concentrações estudadas, respectivamente.

Os resultados de viscosidade demonstram que todas as soluções estudadas apresentam comportamento Newtoniano a baixas taxas de cisalhamento. A viscosidade das soluções aumenta com o aumento da concentração de PA 6,6 da solução, como esperado, devido ao maior emaranhamento entre as cadeias poliméricas ${ }^{[20,38,39]}$. Para soluções de igual concentração observa-se um ligeiro aumento da viscosidade com o aumento da concentração de argila na solução, mas o comportamento da curva de viscosidade em função da taxa continua sendo Newtoniano.

As soluções de PA 6,6 com concentrações de 20, 22,5 e $25 \% \mathrm{~m} / \mathrm{V}$ em grãos apresentaram viscosidade zero $\left(\eta_{\mathrm{o}}\right)$ de 0,39 , 0,87 e 1,14 Pa.s e quando processadas no Haake de 0,59, 1,42 e 1,82 Pa.s, respectivamente. Portanto, as soluções da PA 6,6 processadas, apresentaram maiores valores de $\eta_{0}$ em relação às soluções da PA 6,6 não processadas. Lembrando que a PA 6,6 em questão foi pós-condensada à $150{ }^{\circ} \mathrm{C}$ por 24 horas, provavelmente 

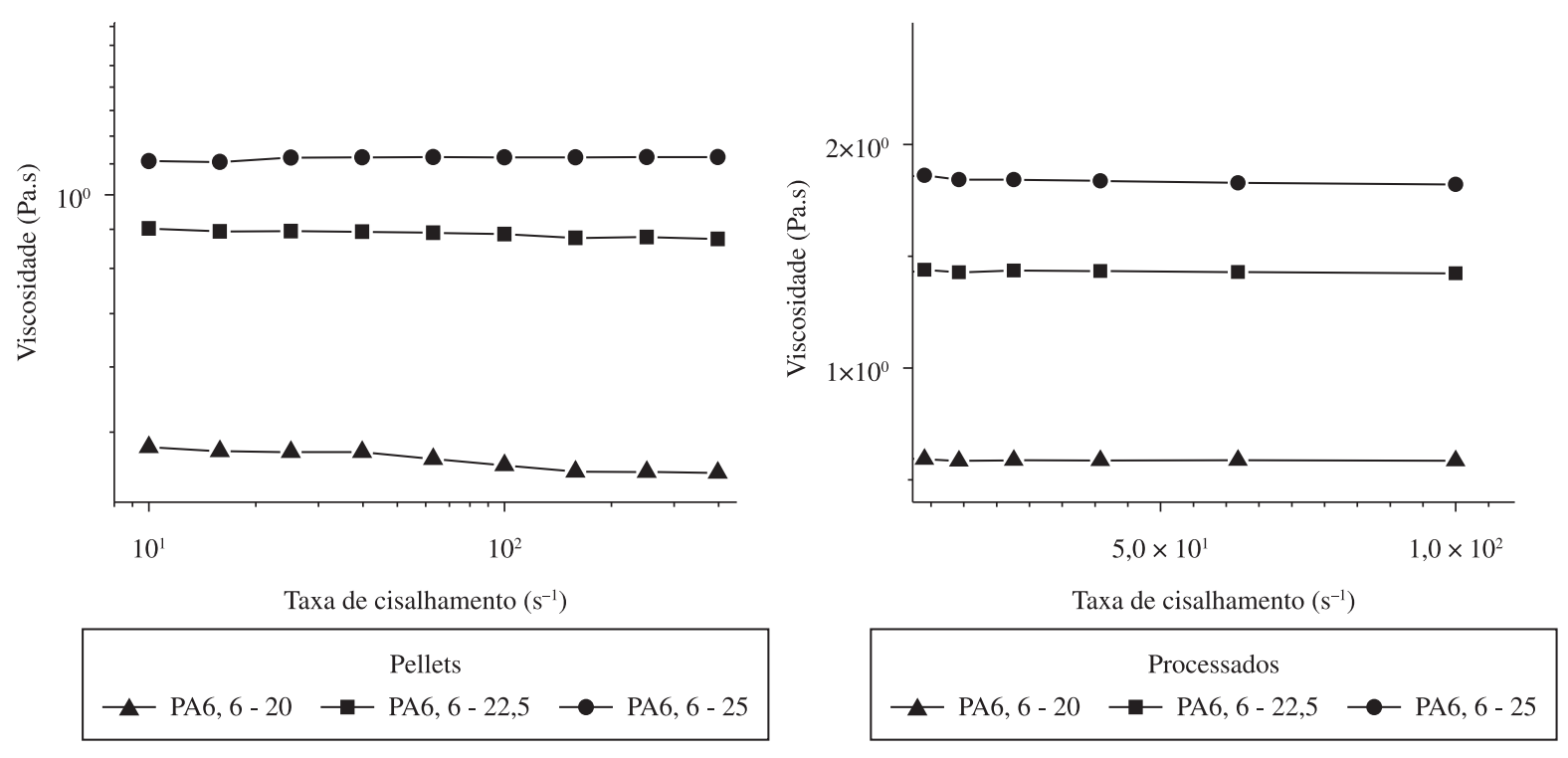

(a)

(b)

Figura 3. Curvas de viscosidade vs. taxa de cisalhamento das soluções de a) PA 6,6 em grãos; e b) processada no Haake.

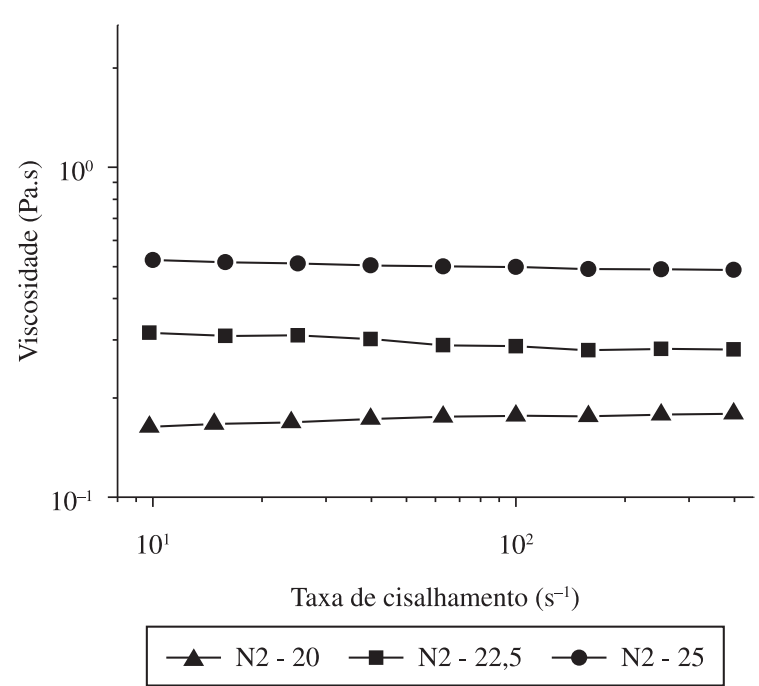

(a)

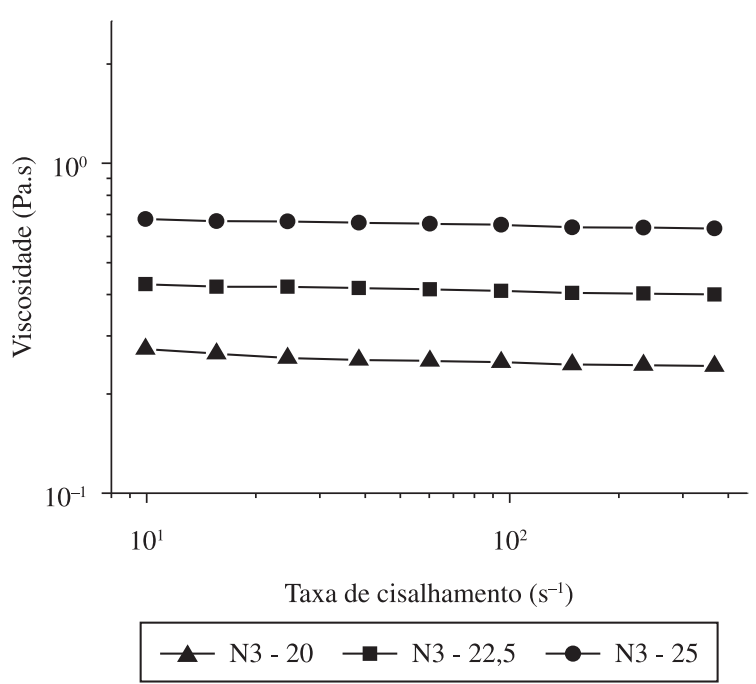

(b)

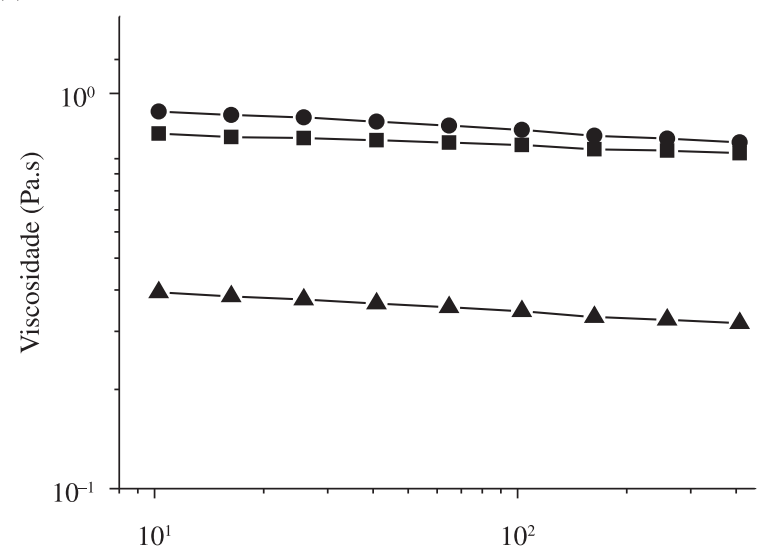

Taxa de cisalhamento $\left(\mathrm{s}^{-1}\right)$

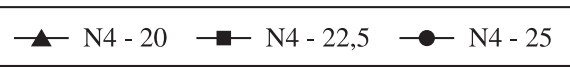

(c)

Figura 4. Curvas de viscosidade $v$ s. taxa de cisalhamento das soluções de: a) N2; b) N3; e c) N4. 
ainda restou uma quantidade de monômero residual suficiente para que durante o processamento no Haake tenha ocorrido nova póscondensação, aumentando novamente a massa molar do polímero. Isto explicaria o fato das soluções de PA 6,6 processadas no Haake apresentarem maiores viscosidades que as soluções da PA 6,6 em grãos, ou seja, não processadas.

Os resultados mostram também que as soluções dos nanocompósitos apresentaram menores viscosidades que a solução do polímero puro que não passou por prévio processamento (pellets). A adição de argila aumentou o caráter pseudoplástico da solução, ou seja, as partículas rígidas da nanoargila atuaram como plastificante diminuindo a viscosidade do material. A ação da argila como plastificante também foi observada por Beatrice e colaboradores ${ }^{[6,14]}$, que mostraram que o comportamento pseudoplástico de fundidos ou soluções poliméricas com cargas minerais está associado a orientação das partículas anisotrópicas da carga com aumento de taxa de cisalhamento. Demais resultados de $\eta_{0}$ das soluções estudadas estão listados na Tabela 1.

\section{Caracterização das mantas nanofibrílicas}

A Figura 5 apresenta os difratogramas DRX das 18 mantas nanofibrílicas eletrofiadas a partir das soluções dos nanocompósitos obtidos via mistura no estado fundido.

Através dos difratogramas pode-se observar que nenhuma das amostras apresentou pico de difração referente ao plano (001) da argila, indicando a formação de estruturas totalmente esfoliadas. Sendo assim, é possível afirmar que o grau de esfoliação dos nanocompósitos foi mantido após o processo de eletrofiação e, portanto, um dos objetivos desta pesquisa foi alcançado com sucesso.
As Figuras 6-8 apresentam as micrografias MEV das mantas nanofibrílicas obtidas para os nanocompósitos N2, N3 e N4, respectivamente. A Tabela 3 também apresenta o diâmetro médio das fibras calculado a partir das micrografias MEV das diferentes mantas obtidas.

Analisando as micrografias MEV é possível concluir que as fibras visualmente se apresentam uniformes, homogêneas, sem porosidade e possuem formato cilíndrico, evidenciando assim que o processo de obtenção das nanofibras foi adequado. Os resultados também mostram que, em relação à PA 6,6 pura, um ligeiro aumento no diâmetro das nanofibras para os nanocompósitos foi observado. Trabalhos recentes ${ }^{[18,20]}$ descrevem valores de diâmetros médios na faixa de 60 a $118 \mathrm{~nm}$, para o mesmo polímero, em concentrações de 15,17 e $20 \% \mathrm{~m} . \mathrm{V}^{-1}$. Neste trabalho, o diâmetro médio das nanofibras dos nanocompósitos variou na faixa de 64 a $146 \mathrm{~nm}$. Comparandose os nanocompósitos com diferentes quantidades de argila e mantendo-se as demais variáveis fixas, pode-se concluir, em geral, que a adição de argila não alterou significativamente o diâmetro médio das nanofibras obtidas, pois houve uma pequena diminuição do diâmetro das fibras. Esses resultados confirmam os dados de reologia obtidos, pois, como discutido anteriormente, apenas um ligeiro decréscimo da viscosidade com o aumento da concentração de argila nas soluções foi observado, e conseqüentemente uma pequena diminuição do diâmetro médio das fibras seria esperado.

Em relação à concentração polimérica dos nanocompósitos, para mantas com a mesma concentração de argila, observou-se um aumento do diâmetro médio das nanofibras com o aumento da concentração polimérica. Aumento significativo na viscosidade das soluções de poliamida 6 em ácido fórmico ${ }^{[14,16]}$ e de poliestireno em mistura de tetrahidrofurano e dimetilformamida ${ }^{[31]}$ com a adição de argila montmorilonita foi observado. Os autores notaram que esse

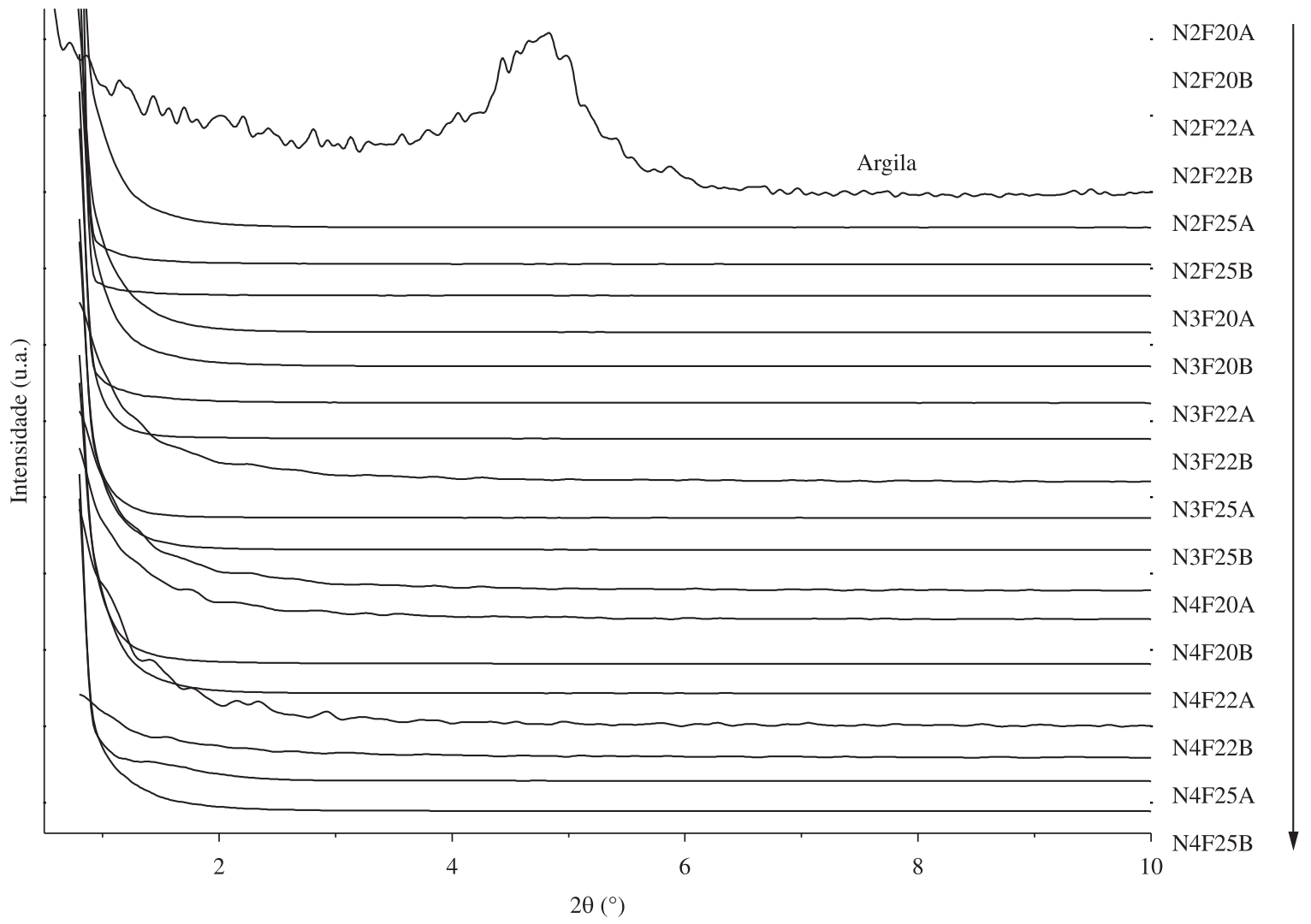

Figura 5. Difratogramas de DRX da argila Cloisite ${ }^{\circledR} 30 \mathrm{~B}$ e das mantas nanofibrílicas eletrofiadas dos nanocompósitos obtidos via mistura no estado fundido. 


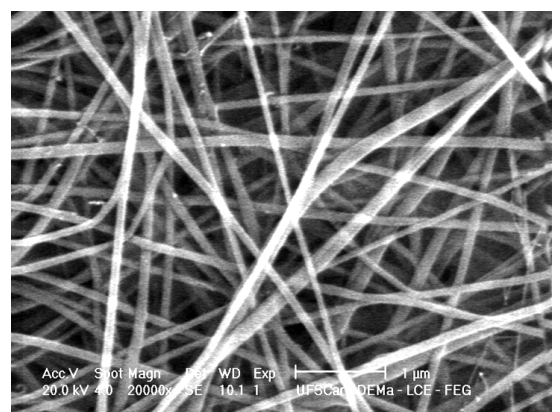

$\mathrm{N} 2 \mathrm{~F} 20 \mathrm{~A}$

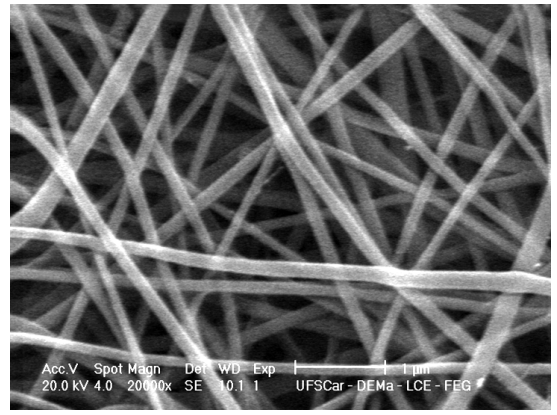

$\mathrm{N} 2 \mathrm{~F} 22 \mathrm{~B}$

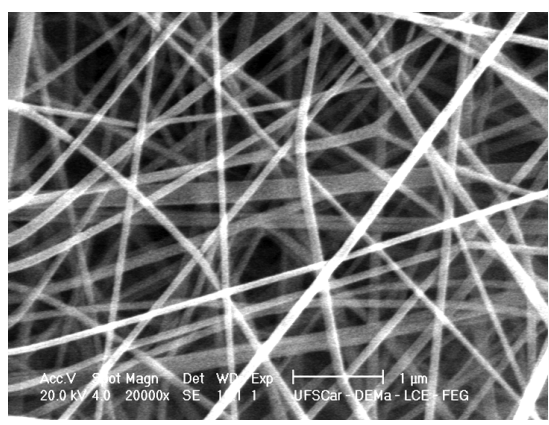

$\mathrm{N} 2 \mathrm{~F} 20 \mathrm{~B}$

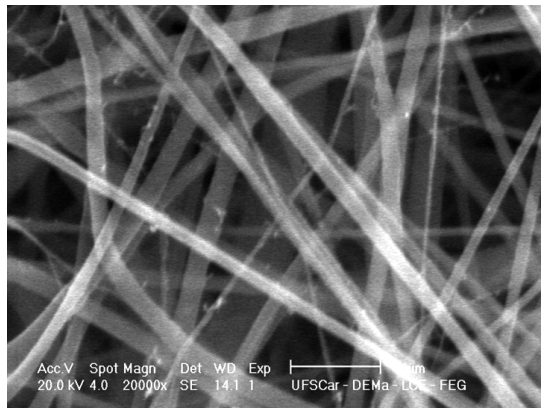

$\mathrm{N} 2 \mathrm{~F} 25 \mathrm{~A}$

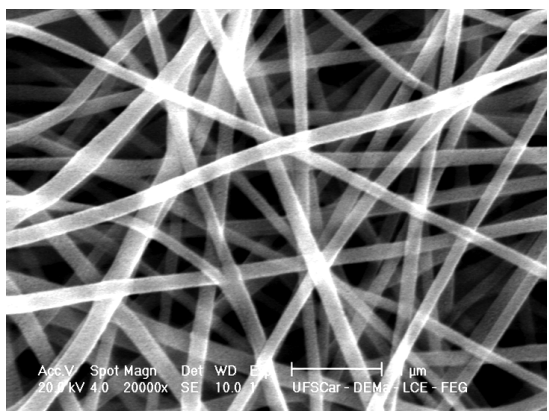

$\mathrm{N} 2 \mathrm{~F} 22 \mathrm{~A}$

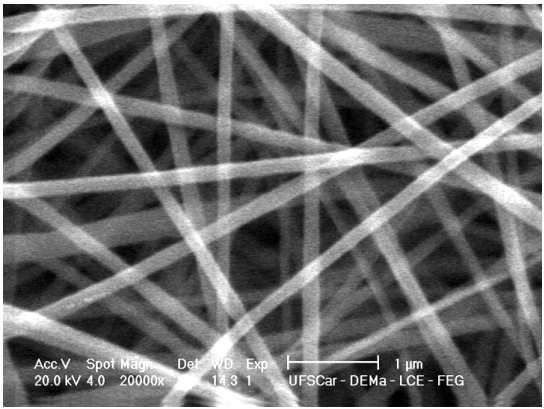

$\mathrm{N} 2 \mathrm{~F} 25 \mathrm{~B}$

Figura 6. Micrografias MEV das mantas nanofibrílicas do nanocompósito N2.

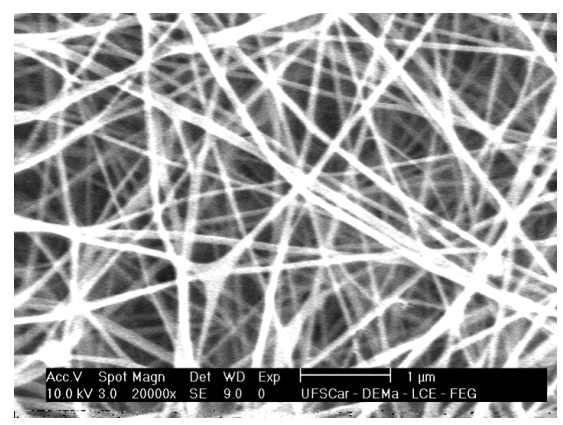

$\mathrm{N} 3 \mathrm{~F} 20 \mathrm{~A}$

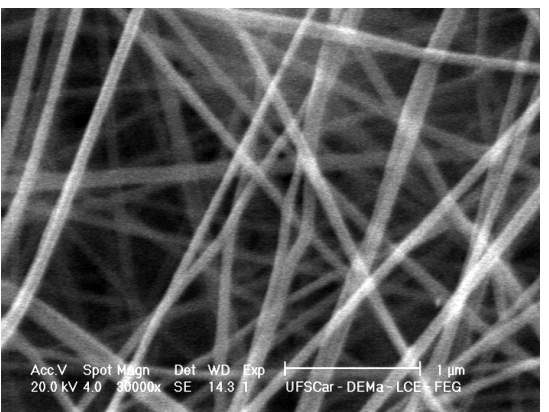

N3F22B

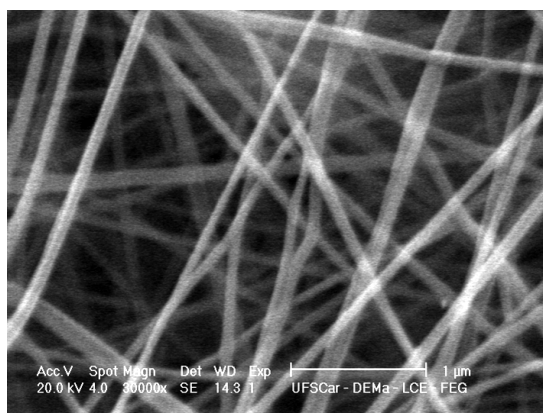

N3F20B

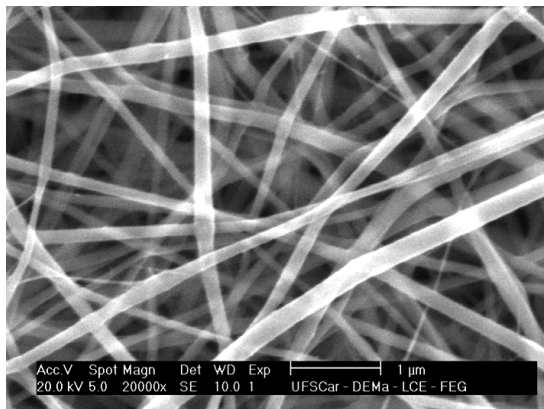

N3F25A

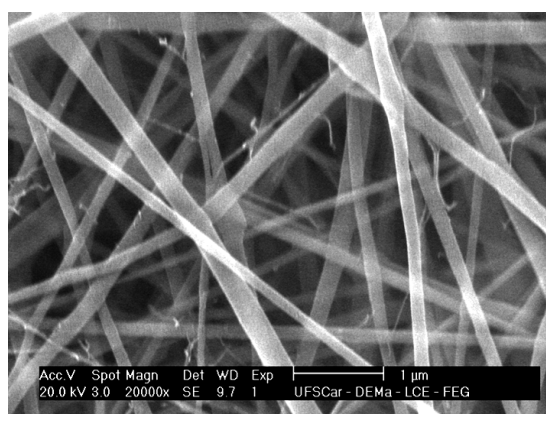

$\mathrm{N} 3 \mathrm{~F} 22 \mathrm{~A}$

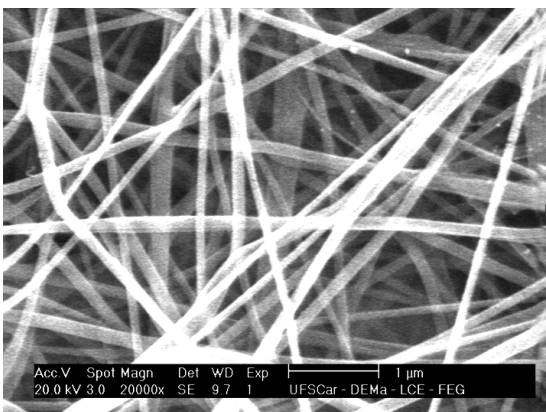

N3F25B

Figura 7. Micrografias MEV das mantas nanofibrílicas do nanocompósito N3.

aumento de viscosidade causou aumento no diâmetro médio das fibras. Porém, vale ressaltar que eles trabalharam com poliamida 6 de massa molar $\mathrm{M}_{w}$ de $100.000 \mathrm{~g} \cdot \mathrm{mol}^{-1}$ e com poliestireno de $\mathrm{M}_{w}$ de 280.000 g. $\mathrm{mol}^{-1}$, ou seja, bem superiores ao utilizado no presente trabalho.

Mantendo-se as demais variáveis fixas e observando apenas a variação do campo elétrico aplicado, nota-se uma tendência na diminuição do diâmetro médio das fibras à medida que se diminui o campo elétrico aplicado. Novamente, essa é uma tendência geral e não uma regra, pois, por exemplo, as mantas N3F22A e N3F22B apresentaram diâmetros médios de 122 e $138 \mathrm{~nm}$, respectivamente, ou seja, neste caso o diâmetro médio aumentou. Dados da literatura $^{[18,37,40]}$ descrevem que quanto menor o campo elétrico aplicado, menor será a vazão da solução polimérica como resposta à diminuição da força eletrostática e, conseqüentemente, menor o diâmetro das fibras. Os pesquisadores concluíram que a diminuição do diâmetro das fibras com o aumento da distância de trabalho ocorre porque o solvente possui maior tempo para evaporar e com 
isso há maior facilidade no espalhamento dos fluídos. Entretanto, Sukigara e colaboradores ${ }^{[41]}$ descrevem que existe um valor crítico de concentração da solução polimérica associada à distância de trabalho que implica neste comportamento de diminuição do diâmetro da fibra, porém acima deste valor crítico ocorre o inverso.

Conclusivamente, pode-se verificar que os menores diâmetros das nanofibras e baixo desvio padrão nos nanocompósitos de PA 6,6 com argila montmorilonita foram obtidos nas seguintes condições: concentração de argila de 3 e $4 \% \mathrm{~m} . \mathrm{V}^{-1}$, concentração da solução polimérica de $20 \% \mathrm{~m} . \mathrm{V}^{-1}$ e campo elétrico aplicado de $2,5 \mathrm{kV} . \mathrm{cm}^{-1}$.

A Figura 9a-c apresenta as micrografias MET das amostras de nanofibras dos nanocompósitos N2, N3 e N4, respectivamente. Nessas micrografias é possível observar visualmente a boa esfoliação da nanoargila na matriz polimérica e o alinhamento das lamelas de argila montmorilonita paralelo ao eixo das fibras, como indicado por setas e círculos nas micrografias. Resultados semelhantes também foram observados em trabalhos ${ }^{[14,15,42]}$ com mantas de nanocompósitos de poliamida 6 e nanoargila Cloisite ${ }^{\circledR} 30 \mathrm{~B}$, obtidos via mistura no estado fundido. Os autore ${ }^{[14,42]}$ ainda observaram, através de resultados de DRX e MET, que os nanocompósitos de poliamida 6 apresentaram maior grau de esfoliação que os de poliamida 6,6 .
O comportamento térmico da PA 6,6 e das mantas eletrofiadas foi avaliado por análise de DSC. A Figura 10 apresenta o termograma obtido para a PA 6,6 pura em grãos e um termograma típico e representativo de todas as amostras de mantas dos nanocompósitos estudados. Os resultados da análise dos termogramas obtidos foram resumidos na Tabela 4.

Analisando o termograma representativo de todas as amostras de mantas dos nanocompósitos estudados, observa-se na curva de aquecimento a presença de uma endoterma na faixa de 30 a $80{ }^{\circ} \mathrm{C}$, antes do pico de fusão. Esta endoterma pode ser associada a três processos: transição Brill, endoterma pré-fusão e evaporação do solvente residual. A transição Brill seria a temperatura no qual a fase cristalina $\gamma$ da PA 6,6 é formada, e apresenta-se como uma endoterma difusa e pequena que geralmente ocorre entre a $\mathrm{T}_{\mathrm{m}}$ $\left(265^{\circ} \mathrm{C}\right)$ e a $\mathrm{T}_{\mathrm{g}}\left(50^{\circ} \mathrm{C}\right)$. Esta transição foi encontrada em poliamida 6 e 6,6 não orientados quando submetidos a condições específicas de tratamento e ocorre entre 80 e $170{ }^{\circ} \mathrm{C}$ para a poliamida 6 e entre 130 e $230{ }^{\circ} \mathrm{C}$ para a poliamida 6,6 . No caso da endoterma de pré-fusão, essa ocorre devido a um processo de relaxação das mantas, e também foi observada em mantas de poliamida $6^{[43]}$. Em relação ao terceiro processo, é sabido que a PA 6,6 é um polímero

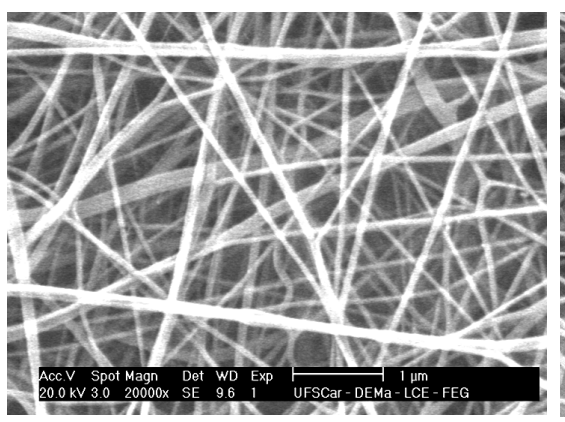

N4F20A

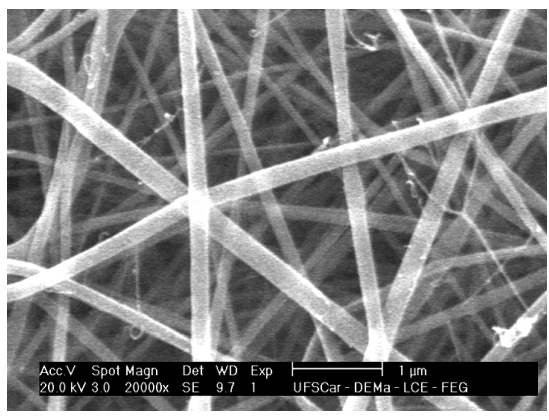

N4F22B

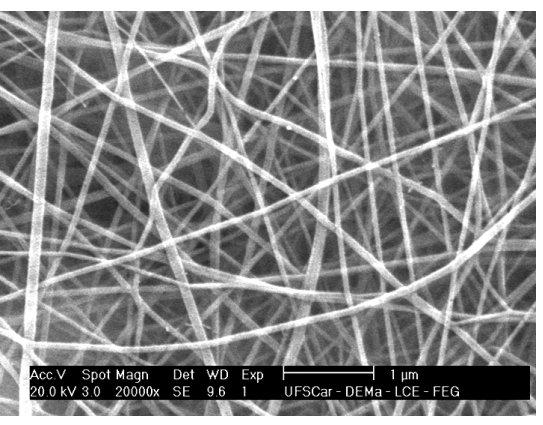

N4F20B

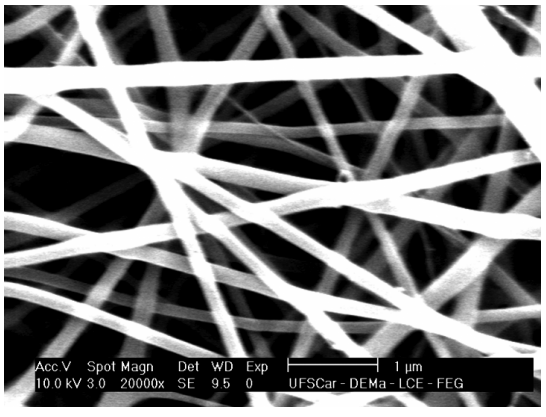

N4F25A

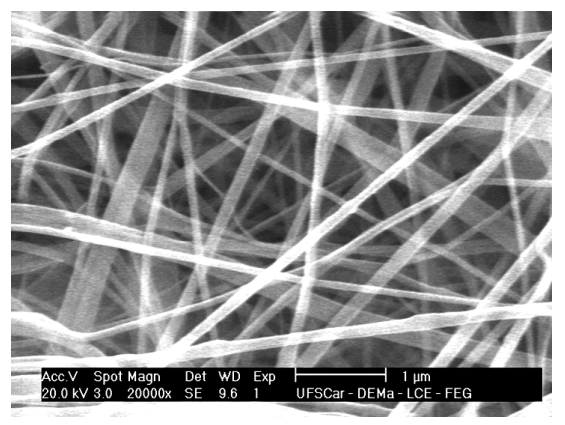

N4F22A

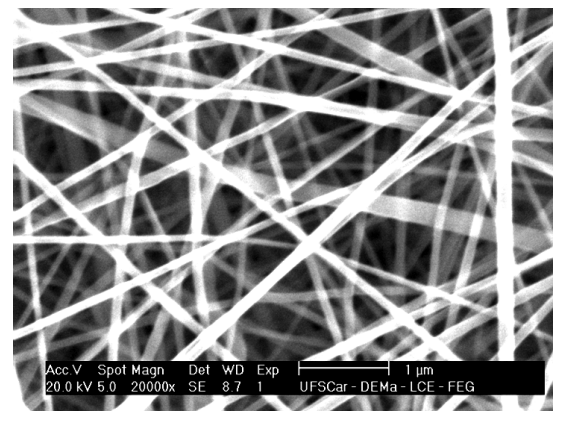

N4F25B

Figura 8. Micrografias MEV das mantas nanofibrílicas do nanocompósito N4.

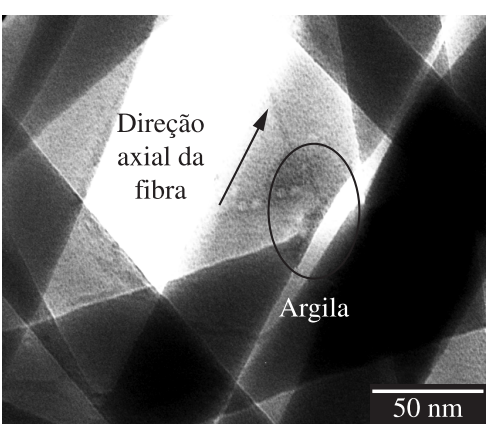

(a)

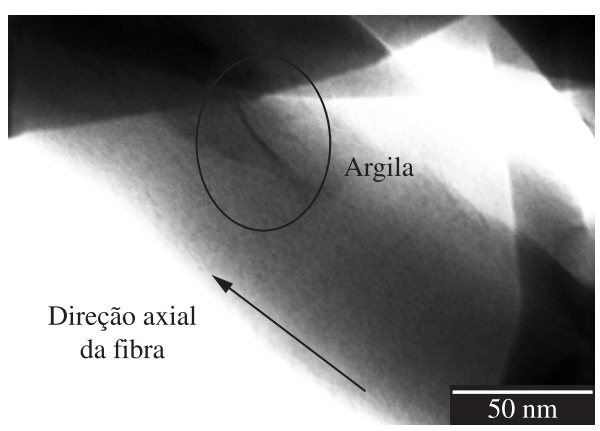

(b)

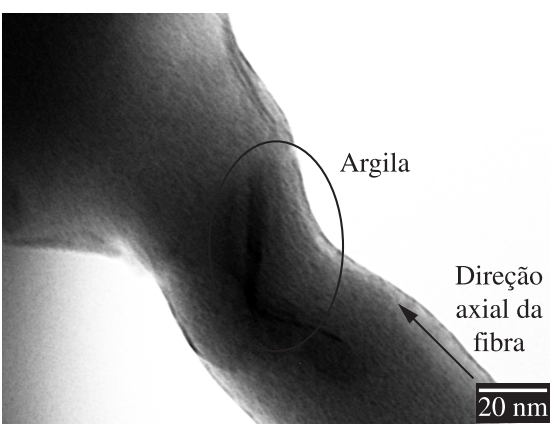

(c)

Figura 9. Micrografia MET das mantas nanofibrílicas dos nanocompósitos: a) N2F25B; b) N3F25B; e c) N4F25B. 
que absorve aproximadamente $8 \%$ em massa de água. Sendo assim, a endoterma encontrada também pode ser referente à evaporação da água absorvida juntamente com a evaporação do solvente residual. No nosso caso, esse terceiro processo é o mais provável uma vez que para a preparação das soluções para a eletrofiação os nanocompósitos não foram previamente secos. A porcentagem de solvente residual nas mantas processadas dos nanocompósitos foi calculada de acordo com a equação 2, ficando em torno de 3 a $19 \%$. Mantas de PA 6,6 pura apresentaram de 2 a 5\% de solvente residual ${ }^{[18,20]}$.

A fibra têxtil de PA 6,6 geralmente possui porcentual de cristalinidade em torno de $40 \%$. Em trabalhos recentes ${ }^{[18,20]}$ com mantas eletrofiadas de PA 6,6 foi encontrado porcentual de cristalinidade entre 15 e $30 \%$, ou seja, menor cristalinidade quando comparadas com a fibra têxtil. Neste trabalho, a cristalinidade calculada para as nanofibras dos nanocompósitos ficou entre 24 e $39 \%$.

Observando a Tabela 4 e comparando os valores obtidos para as mantas com o obtido para o polímero puro em pellets, verifica-se um aumento acima de $13{ }^{\circ} \mathrm{C}$ na $\mathrm{T}_{\mathrm{c}}$ e menores valores de $\Delta \mathrm{H}_{\mathrm{c}}$ das mantas, indicando que as mantas dos nanocompósitos cristalizam antes da PA 6,6. A forma da curva do termograma representativo das mantas eletrofiadas (Figura 10) permite concluir que não houve degradação do polímero quando preparada a solução em ácido fórmico e/ou aplicado o campo elétrico no processamento.

Com relação às variáveis de processo, observa-se que existe uma tendência de diminuição da entalpia de fusão e da entalpia de cristalinidade com a redução do campo elétrico aplicado durante o processo de eletrofiação (Tabela 4).

\section{Caracterização das mantas obtidas via mistura em solução}

As mantas eletrofiadas a partir das soluções dos nanocompósitos (preparadas via mistura em solução e de acordo com as condições

Tabela 4. Valores de temperatura de fusão $\left(\mathrm{T}_{\mathrm{m}}\right)$, temperatura de cristalização $\left(T_{c}\right)$, entalpia de fusão $\left(\Delta H_{m}\right)$, entalpia de cristalização $\left(\Delta H_{c}\right)$, entalpia de vaporização do solvente $\left(\Delta \mathrm{H}_{\mathrm{v}}\right)$, porcentagem de solvente residual $\left(\mathrm{X}_{\mathrm{s}, \mathrm{r}}\right)$, e grau de cristalinidade $(\% \mathrm{C})$ das amostras.

\begin{tabular}{|c|c|c|c|c|c|c|c|}
\hline Amostra & $\begin{array}{c}\Delta \mathbf{H}_{\mathrm{v}} \\
\left(\mathbf{J} . \mathrm{g}^{-1}\right) \\
( \pm \mathbf{1})\end{array}$ & $\begin{array}{l}X_{\mathrm{s} . \mathrm{r}} \\
(\%) \\
( \pm \mathbf{1})\end{array}$ & $\begin{array}{c}\mathbf{T}_{\mathrm{m}} \\
\left({ }^{\circ} \mathbf{C}\right) \\
( \pm \mathbf{0}, \mathbf{5})\end{array}$ & $\begin{array}{c}\Delta \mathbf{H}_{\mathrm{m}} \\
\left(\mathbf{J}^{\left.-g^{-1}\right)}\right. \\
( \pm \mathbf{0 , 5})\end{array}$ & $\begin{array}{l}\% \mathrm{C} \\
(\%) \\
( \pm 1)\end{array}$ & $\begin{array}{c}T_{c} \\
\left({ }^{\circ} \mathbf{C}\right) \\
( \pm 0,5)\end{array}$ & $\begin{array}{c}\Delta \mathbf{H}_{\mathrm{c}} \\
\left(\mathbf{J} . \mathrm{g}^{-1}\right) \\
( \pm \mathbf{0 , 5})\end{array}$ \\
\hline PA 6,6 pellet & - & - & 263,0 & 77,5 & 38 & 220,0 & 62,4 \\
\hline $\mathrm{N} 2 \mathrm{~F} 20 \mathrm{~A}$ & 31 & 11 & 263,8 & 72,6 & 35 & 234,6 & 53,2 \\
\hline $\mathrm{N} 2 \mathrm{~F} 20 \mathrm{~B}$ & 35 & 13 & 262,6 & 79,9 & 37 & 235,8 & 62,2 \\
\hline $\mathrm{N} 2 \mathrm{~F} 22 \mathrm{~A}$ & 50 & 18 & 263,0 & 65,7 & 32 & 235,3 & 40,6 \\
\hline $\mathrm{N} 2 \mathrm{~F} 22 \mathrm{~B}$ & 25 & 11 & 261,6 & 56,3 & 27 & 235,2 & 43,1 \\
\hline $\mathrm{N} 2 \mathrm{~F} 25 \mathrm{~A}$ & 54 & 19 & 264,7 & 78,8 & 38 & 237,5 & 56,5 \\
\hline $\mathrm{N} 2 \mathrm{~F} 25 \mathrm{~B}$ & 23 & 9 & 261,8 & 62,9 & 31 & 235,5 & 46,1 \\
\hline N3F20A & 28 & 10 & 262,2 & 81,2 & 39 & 233,5 & 47,4 \\
\hline N3F20B & 21 & 8 & 262,8 & 51,6 & 25 & 233,2 & 32,3 \\
\hline $\mathrm{N} 3 \mathrm{~F} 22 \mathrm{~A}$ & 25 & 10 & 262,8 & 74,7 & 36 & 234,4 & 47,4 \\
\hline N3F22B & 30 & 12 & 262,3 & 73,7 & 36 & 233,6 & 48,5 \\
\hline $\mathrm{N} 3 \mathrm{~F} 25 \mathrm{~A}$ & 21 & 8 & 263,4 & 71,2 & 35 & 233,9 & 51,4 \\
\hline N3F25B & 10 & 3 & 263,8 & 49,7 & 24 & 233,0 & 33,3 \\
\hline N4F20A & 48 & 19 & 261,7 & 78,2 & 38 & 234,8 & 60,7 \\
\hline N4F20B & 14 & 5 & 262,0 & 67,2 & 33 & 234,2 & 45,7 \\
\hline N4F22A & 40 & 15 & 262,5 & 78,9 & 38 & 235,8 & 55,0 \\
\hline N4F22B & 23 & 8 & 262,2 & 77,3 & 38 & 236,0 & 49,1 \\
\hline N4F25A & 18 & 7 & 264,1 & 70,8 & 34 & 233,9 & 48,1 \\
\hline N4F25B & 27 & 10 & 262,0 & 78,9 & 38 & 233,2 & 52,4 \\
\hline
\end{tabular}

descritas na Tabela 2 foram inicialmente caracterizadas por DRX. A Figura 11 apresenta os difratogramas obtidos para essas mantas e para a argila Cloisite ${ }^{\circledR} 30 \mathrm{~B}$ pura.

Pode-se observar nos difratogramas que o pico referente ao plano (001) da argila em $2 \theta=4,8^{\circ}$ não deslocou para a esquerda nas mantas, indicando que não houve formação de uma estrutura esfoliada ou intercalada, ou seja, as lamelas da nanoargila continuam formando uma fase distinta da fase polimérica conservando a organização lamelar, onde se têm aglomerações das camadas de argila, podendo ser chamado de um microcompósito. Esse resultado indica que o método de preparação via mistura em solução não é eficaz na preparação de nanocompósitos esfoliados. Consequientemente as demais caracterizações dessas mantas não foram realizadas.

Cabe ressaltar que Fong e colaboradores ${ }^{[15]}$ obtiveram nanofibras de nanocompósitos intercalados de poliamida $6 \mathrm{com} 3 \% \mathrm{~m} / \mathrm{V}$ de argila montmorilonita a partir de soluções preparadas via ultra-

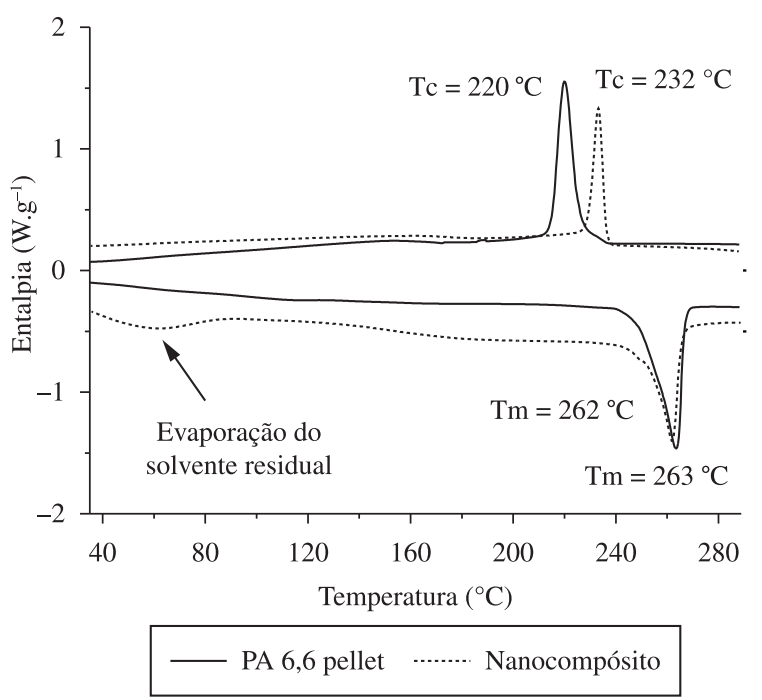

Figura 10. Termogramas DSC da PA 6,6, pura em pellets e típico das mantas dos nanocompósitos de PA 6,6 com Cloisite ${ }^{\circledR} 30 \mathrm{~B}$.

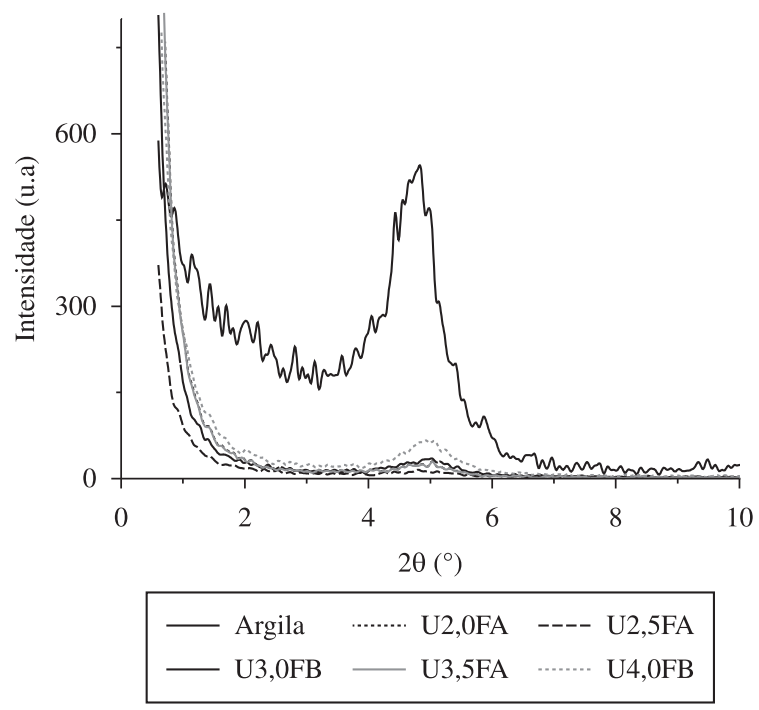

Figura 11. Difratogramas de DRX da argila Cloisite ${ }^{\circledR} 30 \mathrm{~B}$ e das mantas nanofibrílicas eletrofiadas dos nanocompósitos obtidos via mistura em solução. 
som. Eles secaram a argila a $70{ }^{\circ} \mathrm{C}$ por 12 horas antes de preparar as soluções e utilizaram como solvente mistura de hexafluoro-2propanol (HFIP) e dimetilformamida (DMF). Observaram que o HFIP não dispersa bem a argila mesmo com elevado tempo de exposição no ultra-som e que com a adição de DMF notou-se aglomerações de argila, resultando em nanocompósitos intercalados.

\section{Conclusões}

O processo de obtenção do nanocompósito por mistura no estado fundido se mostrou eficiente na esfoliação da nanoargila na matriz polimérica. Resultados de DRX e MET evidenciaram que a boa dispersão e distribuição das lamelas da nanoargila na matriz polimérica foram mantidas mesmo após o processo de eletrofiação. As mantas obtidas, a partir dos parâmetros de processo estudados, apresentaram diâmetro médio na ordem de nanômetros na faixa de 64 a $146 \mathrm{~nm}$. Possuem formato cilíndrico, não são porosas, possuem baixo grau de cristalinidade, entre 24 e $39 \%$, e apresentam entre 3 e $19 \%$ de solvente residual. O processo de obtenção de nanofibras dos nanocompósitos via mistura em solução demonstrou-se ineficaz, pois não foi observada a presença de intercalação e/ou esfoliação das lamelas da nanoargila na matriz polimérica.

\section{Agradecimentos}

Os autores agradecem ao Prof. R. Gregório Filho pelo empréstimo da fonte de alta tensão, ao Prof. A. C. Ruvolo Filho pelas medidas de condutividade elétrica, a Prof. D. F. S. Petri pelas medidas de tensão superficial, e ao CNPq e FAPESP pelo suporte financeiro.

\section{Referências Bibliográficas}

1. Alexandre, M. \& Dubois, P. - Mat. Sci. Eng., 28, p.1 (2000). http:// dx.doi.org/10.1016/S0927-796X(00)00012-7

2. Ray, S. S. \& Okamoto, M. - Progress Polym. Sci., 28, p.1539 (2003).

3. Pinnavaia, T. J. \& Beall, G. W. - "Polymer-Clay Nanocomposites", John Wiley \& Sons, New York (2000).

4. Fornes, T. D.; Yoon, P. J.; Keskkula, H. \& Paul, D. R. - Polymer, 42, p.9929 (2001). http://dx.doi.org/10.1016/S0032-3861(01)00552-3

5. Pozsgay, A.; Frater, T.; Szaszdi, L.; Muller, P.; Sajo, I. \& Pukanszky, B. - Eur. Polym. J., 40, p.27 (2004). http://dx.doi.org/10.1016/j. eurpolymj.2003.09.010

6. Beatrice, C. A. G., Branciforti, M. C., Alves, R. M. V. \& Bretas, R. E. S. - J. Appl. Polym. Sci., 116, p.3581 (2010).

7. Lotti, C.; Issac, C.; Branciforti, M. C.; Alves, R. M. V.; Liberman, S. \& Bretas, R. E. S. - Eur. Polym. J., 44, p.1346-1357 (2008). http://dx.doi. org/10.1016/j.eurpolymj.2008.02.014

8. Favaro, M. M.; Branciforti, M. C. \& Bretas, R. E. S. - Polym. Adv. Tech., 19, p.1 (2008).

9. Marini, J.; Branciforti, M. C. \& Lotti, C. - Polym. Adv. Technol., 21, p.408 (2010).

10. Moretti, F.; Favaro, M. M. ; Branciforti, M. C. \& Bretas, R. E. S. Polym. Eng. Sci., 50, p.1326 (2009). http://dx.doi.org/10.1002/ pen.21662

11. Favaro, M. M.; Rego, B. T.; Branciforti, M. C. \& Bretas, R. E. S. J. Polym. Sci.: Part B: Polym. Phys., 48, p.113 (2010). http://dx.doi. org/10.1002/polb.21852

12. Kojima, Y.; Usuki, A.; Kawasumi, M.; Okada, M.; Fukushima, Y.; Kurauchi, T. E. \& Kamigaito, O. - J. Mat. Res., 8, p.1185 (1993). http:// dx.doi.org/10.1557/jmr.1993.1185

13. Santos, C. R.; Branciforti, M. C.; Canova, T. \& Bretas, R. E. S. "Processo de ontenção de nanofibras de nanocompósitos esfoliados de poliamida 6,6 com nanoargila por eletrofiação e nanofibras obtidas", BR Patente PI0703280-3 (2007).
14. Santos, C. R.; Beatrice, C. A. G.; Branciforti, M. C. \& Bretas, R. E. S. - "Eletrofiação de soluções de nanocompósito de náilon6/ montmorilonita", in: Anais do $9^{\circ}$ Congresso Brasileiro de Polímeros, Campina Grande, Brasil (2007).

15. Fong, H.; Liu, W.; Wang, C. \& Vaia, R. A. - Polymer, 43, p. 775 (2002). http://dx.doi.org/10.1016/S0032-3861(01)00665-6

16. Li, L.; Bellan, L.; Craighead, H. \& Frey, M. W. - Polymer, 47, p.6208 (2006). http://dx.doi.org/10.1016/j.polymer.2006.06.049

17. Kim, G-M..; Michler, G. H.; Ania, F. \& Balta Calleja, F. J. - Polymer, 48, p.4814 (2007). http://dx.doi.org/10.1016/j.polymer.2007.05.082

18. Guerrini, L. M. - "Processamento de Nanofibras por Eletrofiação de Soluções Poliméricas", Tese de Doutorado, Universidade Federal de São Carlos, Brasil (2007).

19. Costa, L. M. M.; Bretas, R. E. S. \& Gregório Filho, R. - Polímeros, 19, p.183 (2009).

20. Guerrini, L. M., Branciforti, M. C., Canova T. \& Bretas, R. E. S. - Mat. Res., 12, p.181 (2009). http://dx.doi.org/10.1590/S151614392009000200012

21. Guerrini, L. M.; Canova, T. \& Bretas, R. E. S. - "Procede dobtention dun produit contenant des nanofibres et produit contenant des nanofibres",FR Patent 0700053 (2007).

22. Guerrini, L. M.; Oliveira, M. P.; Branciforti, M. C. \& Bretas, R. E. S. Polímeros, 16, p.286 (2006).

23. Guerrini, L. M.; Oliveira, M. P.; Branciforti, M. C.; Custódio, T. A. \& Bretas, R. E. S. - J. Appl. Polym. Sci., 112, p.1680 (2009). http:// dx.doi.org/10.1002/app.29673

24. Branciforti, M. C.; Custodio, T. A.; Guerrini, L. M.; Averous, L. \& Bretas, R. E. S.; - J. Macromol. Sci. Phys., 48, p.1222 (2009). http:// dx.doi.org/10.1080/10408390903060970

25. Branciforti, M. C.; Custodio, T. A.; Averous, L. \& Bretas, R. E. S. - "Characterization of Nano-structured Poly(D,L-lactid acid) and Poly(L-lactide acid) Nonwoven Mats Produced via Electrospinning”, in: Anais do $24^{\text {th }}$ Annual Meeting of the Polymer Processing Society, Salermo, Itália (2008).

26. Branciforti, M. C.; Pimenta, J. G.; Averous, L. \& Bretas, R. E. S. - "Preparation and Characterization of Poly(e-caprolactone) Nanofibers", in: Anais do $23^{\text {nd }}$ Annual Meeting of the Polymer Processing Society, Salvador, Brasil (2007).

27. Branciforti, M. C.; Gonçalves, J.; Agnelli, J. A. M. \& Bretas, R. E. S. - "Eletrofiação do Poli(hidroxibutirato)", in: Anais do $18^{\circ}$ Congresso Brasileiro de Engenharia e Ciência dos Materiais, Porto de Galinhas, Brasil (2008).

28. Souza, M. B.; Mendez-Hernandez, D.; Branciforti, M. C. \& Bretas, R. E. S. - "Caracterização de mantas não-tecidas de poli(butileno adipato-co-tereftalato) obtidas por eletrofiação", in: Anais do $19^{\circ}$ Congresso Brasileiro de Engenharia e Ciência dos Materiais, Campos do Jordão, Brasil, (2010).

29. Branciforti, M. C.; Pimenta, J. G.; Averous, L. \& Bretas, R. E. S. - "Biodegradable Poly(e-caprolactone)/ Montmorillonite Nanocomposites: Electrospinning and Characterization", in: Anais do Hybrid Materials, Tour, França (2009).

30. Ristolainen, N; Heikkila, P.; Harlin, A. \& Seppala, J. - Macromol. Mater. Eng., 291, p.114 (2006). http://dx.doi.org/10.1002/mame.200500213

31. Ji, Y.; Li, B.; Ge, S.; Sokolov, J. C. \& Rafailovich, M. H. - Langmuir, 22, p.1321 (2006). PMid:16430300. http://dx.doi.org/10.1021/la0525022

32. Brandup, J.; Immergut, E. H. \& Grulke, E. A. A. - "Polymer Handbook", John Wiley \& Sons, New York (1999).

33. Supaphol, P.; Mit-Uppathan, C. \& Nithitanakul, M. - J. Polym. Sci., 43, p.3699 (2005).

34. Companhia de Tecnologia de Saneamento Ambiental - CETESB. Disponível em: <www.cetesb.gov.br>. Acessado em: 02 jul. 2010. 
35. Naves, A. F. - "Partículas Híbridas de Polissacarídeos o Polímeros Sintéticos", Tese de Mestrado, Universidade de São Paulo, Brasil (2005).

36. Dijkstra, D. J. - Pure Appl. Chem., 81, p.339 (2009). http://dx.doi. org/10.1351/PAC-REP-08-07-22

37. Supaphol, P.; Mit Uppatham, C. \& Nithitanakul, M. - Macromol. Mater. Eng., 290, p.933 (2005). http://dx.doi.org/10.1002/mame.200500024

38. Hiroshi, A.; White, J. L. \& Feller, J. E. - J. Appl. Pol. Sci., 23, p.2293 (1979). http://dx.doi.org/10.1002/app.1979.070230808

39. Bretas, R. E. S. \& Ávila, M. A. - "Reologia de Polímeros Fundidos", Edufscar, São Carlos (2005).
40. Li, Y.; Huang, Z. \& Lü, Y. - Eur. Pol. J., 42, p.1696 (2006). http:// dx.doi.org/10.1016/j.eurpolymj.2006.02.002

41. Sukigara, S.; Gandhi, M.; Aytsede, J.; Micklus, M. \& Ko, F. - Polymer, 45, p.3701 (2004). http://dx.doi.org/10.1016/j.polymer.2004.03.059

42. Chavarria, F. \& Paul, D. R. - Polymer, 45, p.8501 (2004). http://dx.doi. org/10.1016/j.polymer.2004.09.074

43. Simal, A., L. \& Martin, A., R. - J. Appl. Pol. Sci., 68, p.453 (1998).

Enviado: 09/07/10

Reenviado: $16 / 11 / 10$

Aceito: $24 / 03 / 11$

DOI: $10.1590 / \mathrm{S} 0104-14282011005000068$ 